University of Thi_Qar Journal for Engineering Sciences

ISSN :2664- 5572 ( online)

http://www.doi.org/10.31663/tqujes.10.2.366(2019)

ISSN:2664-5564 (print)

Vol 10.2 (September 2019)

Available at http://jeng.utq.edu.iq

utjeng@ utq.edu.iq

\title{
Study The Performance of Double-Acting Stirling Engine
}

\author{
Zahra J.Hansh ${ }^{\dagger}$, Haider J.Abd \\ †First author's Department of Mechanical Engineering, College of Engineering, Thi-Qar University, Iraq. \\ †Second author’s Department of Mechanical Engineering, College of Engineering, Thi-Qar University, Iraq. \\ *Coresponding author, Email: $\underline{\text { Haider-jabaur-abid@utq.edu.iq }}$
}

\begin{abstract}
In this paper, study and design of double acting Stirling engine with one piston conducted .The thermodynamic analysis was developed by using MATLAB program for predict the periodic variation of pressure, specific volumes. The performance prediction of the double-acting Stirling engine was developed using ANSYS 18.2 program. This theoretical study mainly studies the influence of the engine parameter (charge pressure) on the engine performances (engine speed, torque, and power output). The performance of the engine was examined for different values of the charge pressures (1, 3, 6 bar). The results indicated the maximum power and torque $117.8 \mathrm{~W}, 2.5404 \mathrm{~N} . \mathrm{m}$ at $443 \mathrm{rpm}$ when the charge pressure was 6 bars.
\end{abstract}

Keywords: Double-acting stirling engine; Temperature ; charge pressure; engine performance

\section{Introduction}

The Stirling engine is a kind of external combustion heat engine. It is first suggested by Robert Stirling in 1816 (UK, patent no. 4081). Depending on his invention, many Stirling engines were built in different forms and sizes. Stirling cycle engine is less harmful to the environment with high theoretical efficiency and quite operation .In Stirling engine can be use several gases as working fluid, such as air, helium, hydrogen, nitrogen etc. multitude heat sources can be utilize on Stirling engine include combustible materials, biomass, biogas and solar energy[1]. Theoretically, Stirling engine is one of the most efficient thermodynamic engines to convert the heat into mechanical work or useful work. Stirling engine is heat engine operating on theoretical Stirling cycle which undergoes isothermal compression, isothermal expansion, and constant volume heating and constant volume cooling process [2].

In general, Stirling engine is classified into three types of mechanical configurations as follow:

(1) $\alpha$ - type engine configuration has two pistons, called hot and cold pistons, in two separate cylinders. The two pistons are situated with $90^{\circ}$ phase angle in separate cylinders [3].

(2) $\beta$-type engine configuration is have a single cylinder with hot and cold ends. These types of Stirling engine have displacer and power pistons that moves the working fluid between the hot and cold ends. Typically, it use with a rhombic drive to achieve the phase difference between displacer and power pistons, but they can be linked $90^{\circ}$ out of phase on a crank shaft [4].
(3) $\gamma$-engines configuration has two cylinders: one contain displacer, with hot and cold ends, one for the power piston; they are linked to form a single space with same pressure in both cylinders; typically the piston are in parallel and joined $90^{\circ}$ out of phase on a crankshaft [4]

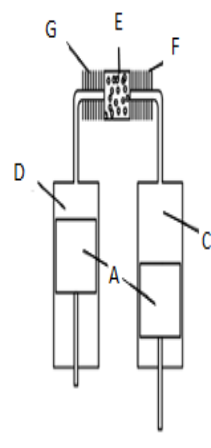

$\alpha$

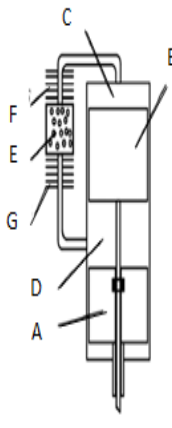

$\beta$

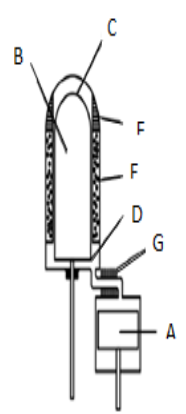

$\gamma$
A-Piston; B-Displacer; C- expansion space; D-Compression space E- Regenerator F-Heater; G-cooler

Fig.1.Three basic arrangements of Stirling engines [1].

Thermodynamic analysis is quite significant in determining the engine performance and parameters that effect on the performance. Several analysis methods were developed since the invention of Stirling engines and engine performance was estimated during the design process. The first analysis for obtaining the thermodynamic performance of Stirling engines were 
proposed by Gustav Schmidt in 1871 and thermodynamic analysis of $\alpha, \beta$ and $\gamma$ type engines were carried out. The Schmidt analysis is based on the isothermal expansion and compression of an ideal gas[1] .

The Schmidt analysis is an ideal thermodynamic analysis used to predict the performance of three types of Stirling engines of $\alpha, \beta$ and $\gamma$ configurations. To determine the possibility of intended engine and predict the performance in the design stage, Schmidt analysis is performed for this purpose. This analysis is take into account the variations of sinusoidal volumes of both compression and expansion cylinder space and thus gives the accurate approximation of actual performance compared with Stirling cycle [5].

In order to develop isothermal model, Finkelstein (1975) [6] and Urieli Rallis and Berchowitz (1977) [7] proposed ideal adiabatic models, in which the thermodynamic process take place in expansion space and compression space are estimated to be adiabatic processes. Gupta et al.(1978) [8] develop 1 and $1.9 \mathrm{~kW}$ solar-powered Stirling engines for rural applications. the efficiencies of engine were determined between $5.5 \%$ and $5.7 \%$ and overall efficiency was estimated $2.02 \%$.

Recently, Kaushik and Kumar (2000)[9] obtained the thermodynamic performance of a Stirling engine by using finite-time thermodynamics. The effects of the temperature of different heat exchangers and heat source on engine power and engine efficiency were investigated. Kongtragool and Wongwises (2006) [10] Conducted theoretical study on the thermodynamic analysis of Stirling engine. The effect of the dead volumes of cold volume, hot volume and regenerator on the performance of Stirling engine was investigated. Timoumi et al. (2008)[11] Studied the effect of regenerator sizes and materials on the performance of a General Motors GPU-3 Stirling engine .Sripakagorn and Srikam (2011) [12] betatype Stirling engine was designed with displacer swept volume $165 \mathrm{cc}$. The working fluid was air. The results showed that the maximum shaft power was obtained 95.4 $\mathrm{W}$ at $360 \mathrm{rpm}$. Aksoy et al.(2017) [13] manufactured and tested a beta- type Stirling engine with rhombic drive mechanism .The tested were carried out for five deferent stages of charge pressure ranging from 1 to 5 bar. The results showed that the maximum torque and power of the engine were determined as 18 N.m and $1215 \mathrm{~W}$ at engine speed 612 and $722 \mathrm{rpm}$ respectively at 4 bar charge pressure. The cyclic work generation of the engine was obtained as $19.27 \mathrm{~J}$ and $25 \mathrm{~J}$ corresponding to 1.3 and 5 bar charge pressure respectively.

\section{Problem statement}

The current study aims to design a new type of Stirling engines that work with one piston. This type of Stirling engines works by pouring compressed air at certain pressures resulting from the exposure of the sun to a tank with a certain dimension. The thermodynamic analysis was developed by using MATLAB program for predict the periodic variation of pressure, specific volumes. In present study, The main objective is to get maximum output of double-acting Stirling engine. The performance prediction of the double-acting Stirling engine was developed using ANSYS 18.2 program .

\section{Thermodynamic analysis of double -acting Stirling engine}

Fig. 2 shows a sketch of the double acting Stirling engine with the notations used for the thermodynamic analysis. To determine the sinusoidal motion of piston in simulation, the analysis trajectories of the piston is a necessary process. The displacement of the piston in cylinder can be seen in Fig.2, it can be written following as bellow:

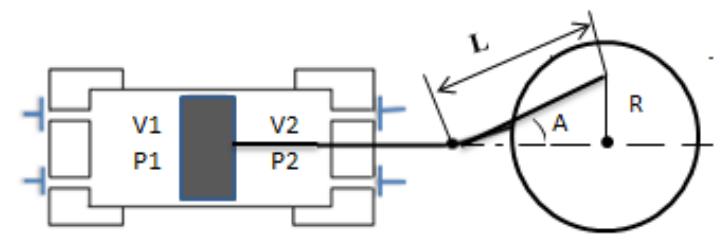

Fig.2 Double -acting Stirling engine scheme.

$$
\mathrm{Xp}=\mathrm{L}+\mathrm{R}-\sqrt{\left(\mathrm{L}^{2}-\mathrm{R}^{2} \sin \mathrm{A}\right)}-\mathrm{R} \cos \mathrm{A}
$$

$\mathrm{Xp}=$ displacement $(\mathrm{m})$

$\mathrm{L}=$ connecting rod length $(\mathrm{m})$

$\mathrm{R}=$ crank radius $(\mathrm{m})$

Therefore, the instantaneous volumes of the piston for any crank angle (A) are given by:

$$
\begin{aligned}
& \mathrm{V}_{1}(A)=\left(A_{\mathrm{lp}} * \mathrm{Xp}\right)+\mathrm{V}_{\mathrm{ld}} \\
& \mathrm{V}_{2}(\mathrm{~A})=\left(\mathrm{A}_{\mathrm{up}} * \mathrm{Xp}\right)+\mathrm{V}_{\mathrm{ud}}
\end{aligned}
$$

Where

$\mathrm{V}_{1}=$ lower volume $\left(\mathrm{m}^{3}\right)$

$\mathrm{V}_{2}=$ upper volume $\left(\mathrm{m}^{3}\right)$

$\mathrm{A}_{\mathrm{lp}}=$ lower area $\left(\mathrm{m}^{2}\right)$

$\mathrm{A}_{\mathrm{up}}=$ upper area $\left(\mathrm{m}^{2}\right)$

$\mathrm{V}_{\mathrm{ld}}=$ lower dead volume $\left(\mathrm{m}^{3}\right)$

$\mathrm{V}_{\mathrm{ud}}=$ upper dead volume $\left(\mathrm{m}^{3}\right)$

\section{* Upward motion}

the working gas is an ideal gas ,there for the ideal gas law can be apple for it.

$$
\mathrm{PV}=\mathrm{mRT}
$$

Therefore, the instantaneous pressure for any crank angle (A) is given by:

$$
\begin{aligned}
& \mathrm{P}_{1}(\mathrm{~A})=\left(1 * \mathrm{TH} /\left(\mathrm{V}_{1}(\mathrm{~A})\right)\right. \\
& \mathrm{P}_{2}(\mathrm{~A})=\left(1 * \mathrm{TC} / \mathrm{V}_{2}(\mathrm{~A})\right)
\end{aligned}
$$

Where $\mathrm{P}_{1}, \mathrm{P}_{2}$ the lower and upper pressure and $\mathrm{T}_{\mathrm{H}}, \mathrm{T}_{\mathrm{C}}$ the hot and cold temperature .

\section{* Downward motion}

In downward motion, the instantaneous pressure for any crank angle $(\mathrm{A})$ is given by:

$$
P_{1}(A)=\left(1-T C /\left(V_{1}(A)\right)\right.
$$




$$
\mathrm{P}_{2}(\mathrm{~A})=\left(1 ; \mathrm{TH} / \mathrm{V}_{2}(\mathrm{~A})\right)
$$

\section{Numerical analysis}

In present study, the main objective is to get maximum output of double-acting Stirling engine. The performance prediction of the double-acting Stirling engine was developed using ANSYS 18.2 program. The geometry tool is important tool in ANSYS that gives the ability to create an engine configuration with the desired design in the simulation program, Table 2 , show the specification of double-acting Stirling engine model. The three-dimensional model, which is shown in Fig.3, has been used for simulation process.

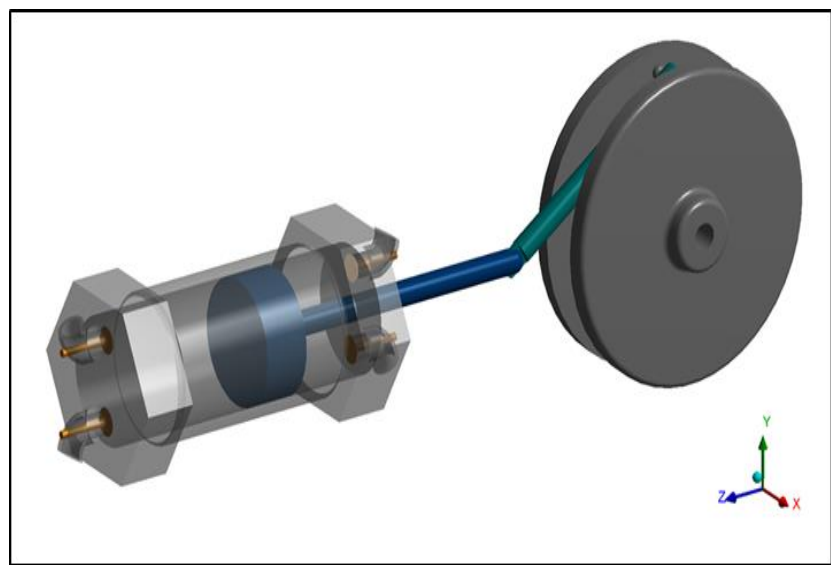

Fig.3. Three dimensional Model of double-acting Stirling engine

Establishing the appropriate mesh is considered the step following after creation of the model to implement simulation. Mesh is an important component for providing high-quality solutions. ANSYS workbench 18.2 provides many types of mesh such as hexahedral and tetrahedral and the mesh may be structured or non-structured. In current study, a tetrahedral mesh is applied as shown in Fig.4. The model has (267719) nodes and the number of elements is (164107). In meshing there are some parameters that help to identify the quality of grid; skewness is the most important one. Skewness determines how generated cells closed to the ideal configuration and it governs solution ability to converge, as listed and shown in figures below. They are shows that grid generated for all computational domains are within very good to excellent presentation for geometry considered. Also this grid has the ability to reach solution convergence for any desired residual values.

Table 2: Design parameters and boundary condition of the double acting Stirling engine

\begin{tabular}{|c|c|}
\hline \multicolumn{2}{|c|}{ Piston } \\
\hline Bore x stroke $(\mathrm{mm})$ & $80 \times 100 \mathrm{~mm}$ \\
\hline Connecting rod length & $180(\mathrm{~mm})$ \\
\hline Crank radius & $50(\mathrm{~mm})$ \\
\hline
\end{tabular}

\begin{tabular}{|c|c|}
\hline \multicolumn{2}{|c|}{ Boundary condition } \\
\hline Charge pressure & $(1-3-6) \mathrm{bar}$ \\
\hline TH (k) & $623 \mathrm{k}$ \\
\hline TC (k) & $300 \mathrm{k}$ \\
\hline
\end{tabular}

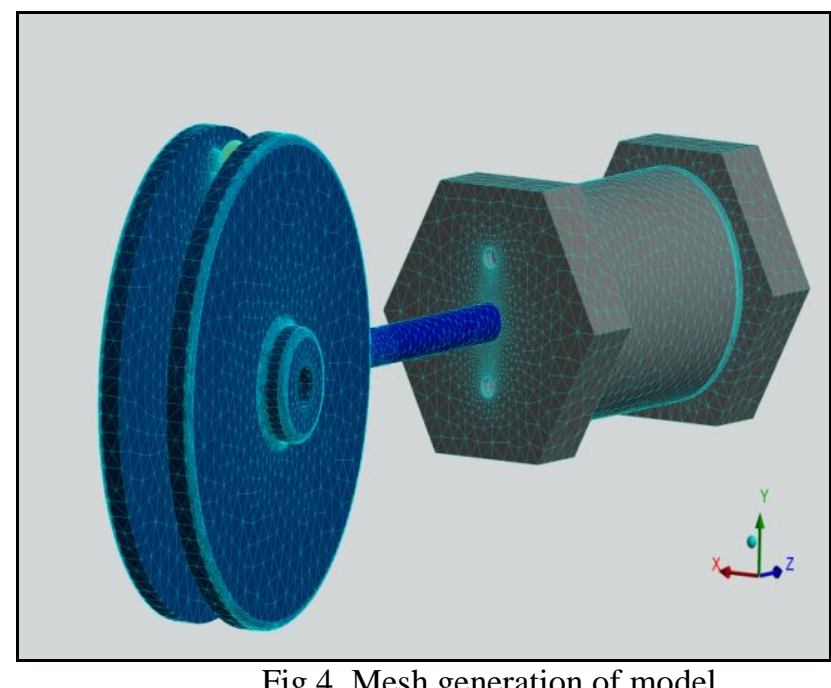

Fig.4. Mesh generation of model

\subsection{Mechanical analysis Description}

In ANSYS program, the mechanical analysis of double-acting Stirling engine is focus of study. Multiphysics simulations that allow for realistic single-piston Stirling engine system solutions have been done and include the following capabilities for Stirling analysis:

I. Structural

-For deformation and torque prediction

II. Rigid

- For moving piston profile

The engine configuration shown in Fig.5, has been developed for multi-mission use (i.e., for use in structural and rigid dynamics).

For structural analysis, the boundary conditions in Fig.5, includes providing mean pressure for a range of $(1,3,6$ bar) in a term of Hydrostatic pressure which applies a linearly varying load to the surface of piston to mimic fluid force acting on the structure. Also, defining the joints which are, by default, detected and contact regions are assigned for face/face conditions.

Multiple steps in solving process used to allow a series of static analyses to be solved sequentially, the end time was used as a counter/tracker to identify the torque at steps and sub-steps. 


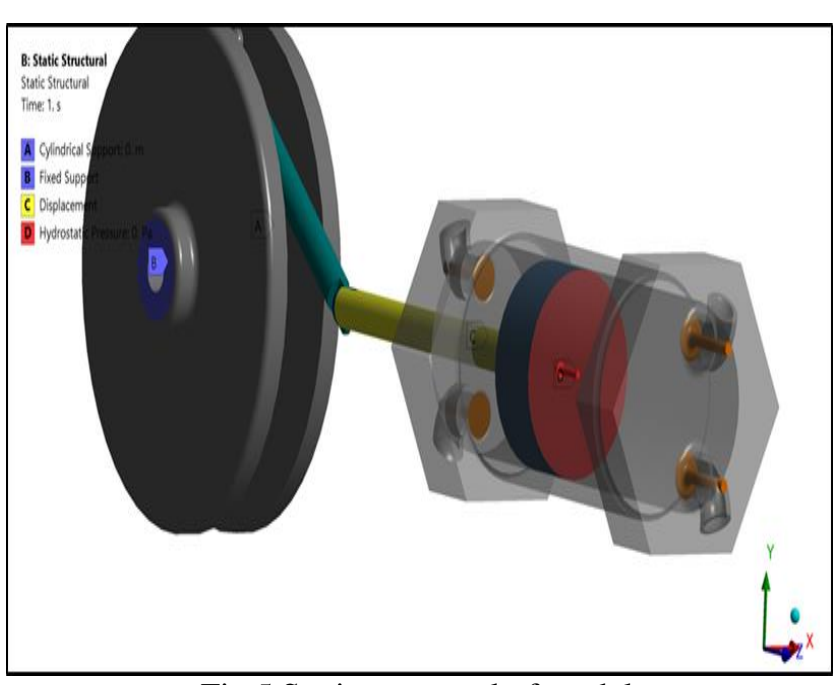

Fig.5.Static structural of model

ANSYS Rigid Dynamics solver was utilized to determine the dynamic response and to study the kinematics of the overall assembly of engine bodies which linked by joints. These joints are idealizations of the contact between the bodies. Joints are characterized by the motion that they allow between the two bodies that they connect.

\subsection{Stress Concentrations}

The stress concentrations caused by the applied pressure on the crankshaft were be better understood by applying numerical methods. Analysis using the finite element method will provide insight into the stress concentrators' magnitude and location as shown in Fig. 6 . A relatively fine mesh of triangular elements is applied to the flywheel solid model. The flywheel is cylindrically supported by a portion of the outer surface corresponding to the location of the shaft. It is supported along the portion of the crank rod joint which contacts the load. The boundary conditions of pressure $(1,3,6)$ bar, as previously determined for an operational condition, is applied to the pin joint which connects the flywheel to the crank rod.

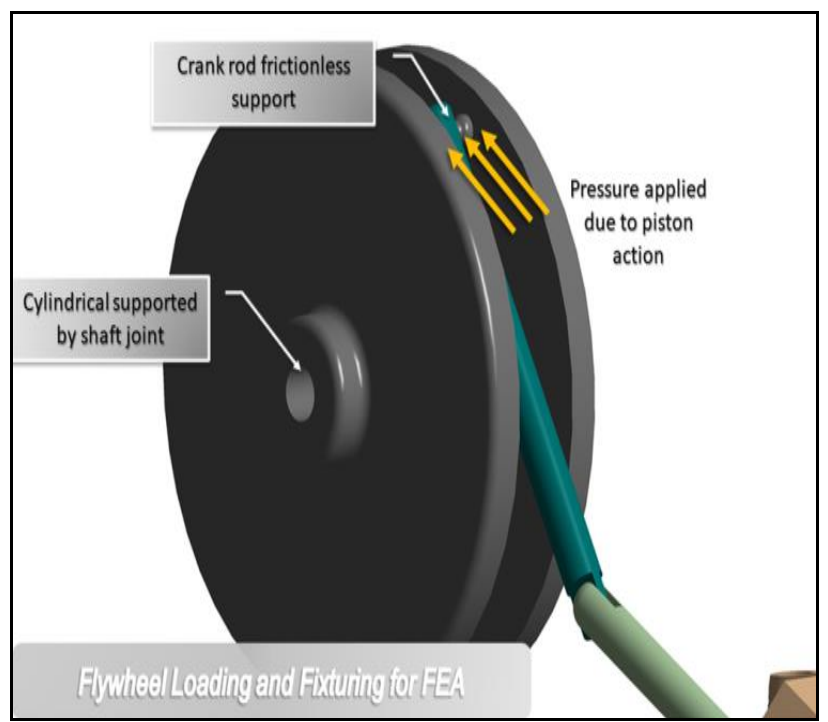

Fig.6. FEA Boundary Conditions for Flywheel Analysis.

\section{Results and discussion}

In this section, the thermodynamic results obtained by MATLAB program that include the variation of volumes and pressure during cycle by using equation in section 3 . In Fig.7 and Fig.8, show the relationship of lower /upper volume and pressure with crank angle.

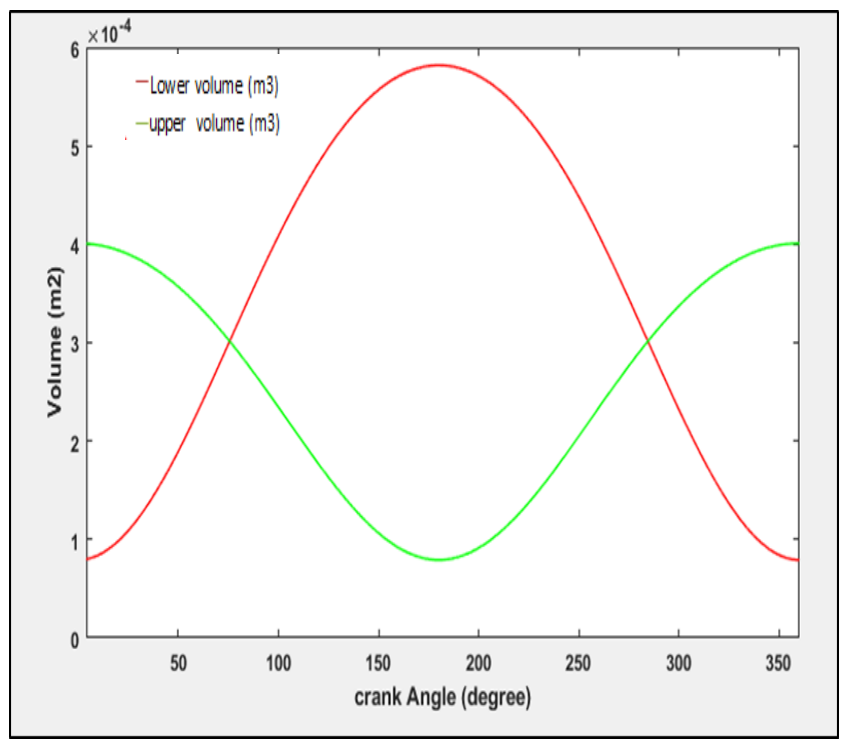

Fig.7 Variations volumes at lower and upper piston with crank angle

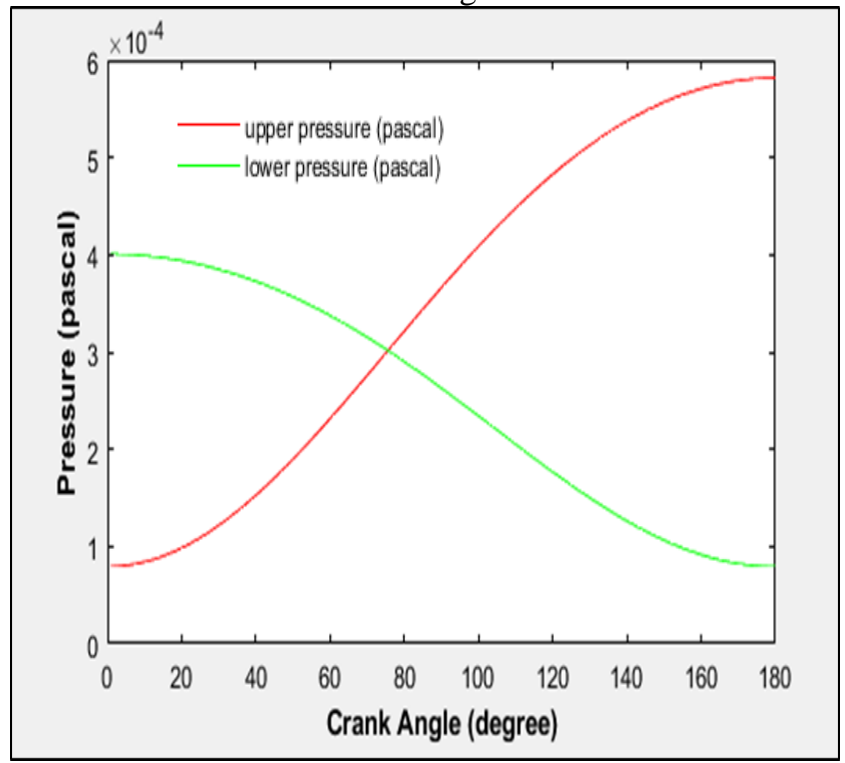

Fig.8 Variations pressures at lower and upper piston.

The torque expansion plots are displayed in Fig.9 for all pressure group (1-3-6 bar) conducted. The time period specified for each pressure is determined as 10 seconds. In Fig.9a, The pressure on the piston surface is approximately the same throughout the analysis period and the mean torque occurs at the flywheel $0.38 \mathrm{Nm}$ during the fixed analysis period (3-10 seconds). However, when the piston is to subjected ( $3 \mathrm{bar}=0.3 \mathrm{MPa}$ ) as in Fig. $9 \mathrm{~b}$, the average torque at the flywheel $(0.778 \mathrm{Nm})$ occurs in the fixed period with an increase of $(104.7368421 \%$ bar $)$ than 
case with (1 bar) pressure. This is due to the increase in the forces resulting from air-flow over the entire system. As a result of the change in the pressure shown in Fig.9c, the average torque value is $(2.356 \mathrm{Nm})$ depending on pressure magnitude 6 bar. The torque in the case of 6 bar. pressure increased by $520 \%$ than its value in the case of 1 bar applied pressure.
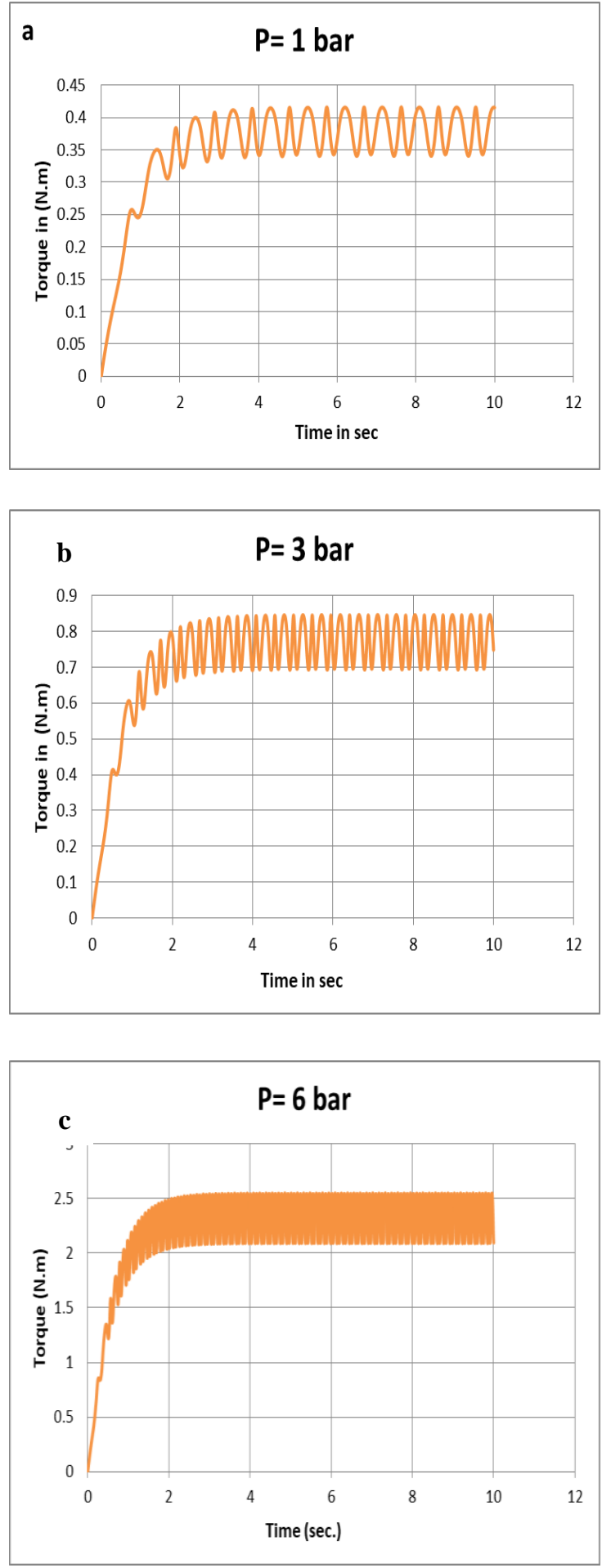

Fig.9. The torque variation with time for pressures values $(1,3,6$ bar $)$ in $\mathrm{a}, \mathrm{b}, \mathrm{c}$.
The flywheel speeds varied as a result of the force exerted on the piston and bottom surfaces. Fig.10, show the variations of speeds of the flywheel for . group (1-3-6 bar). In Fig.10a, shows the speed of the flywheel averaged by $66.67 \mathrm{rpm}$ at the steady period of analysis (from 3-10 sec). The speed increased by ( $120.48 \%$ ) as in Fig.10b, with increasing pressure to be 3 bar more than its value at 1 bar. This is due to the fact that was approved by Newton's Second Law of Motion which described the relationship between the force applied to the system (in our case the pressure) that the rate change of moment of body is directly proportional to the force applied . Due to the continuous increase in pressure values as in Fig.10c, the speed has increased in the case of 6 bar pressure by $(502.97 \%)$ of its value in the case of 1 bar pressure.
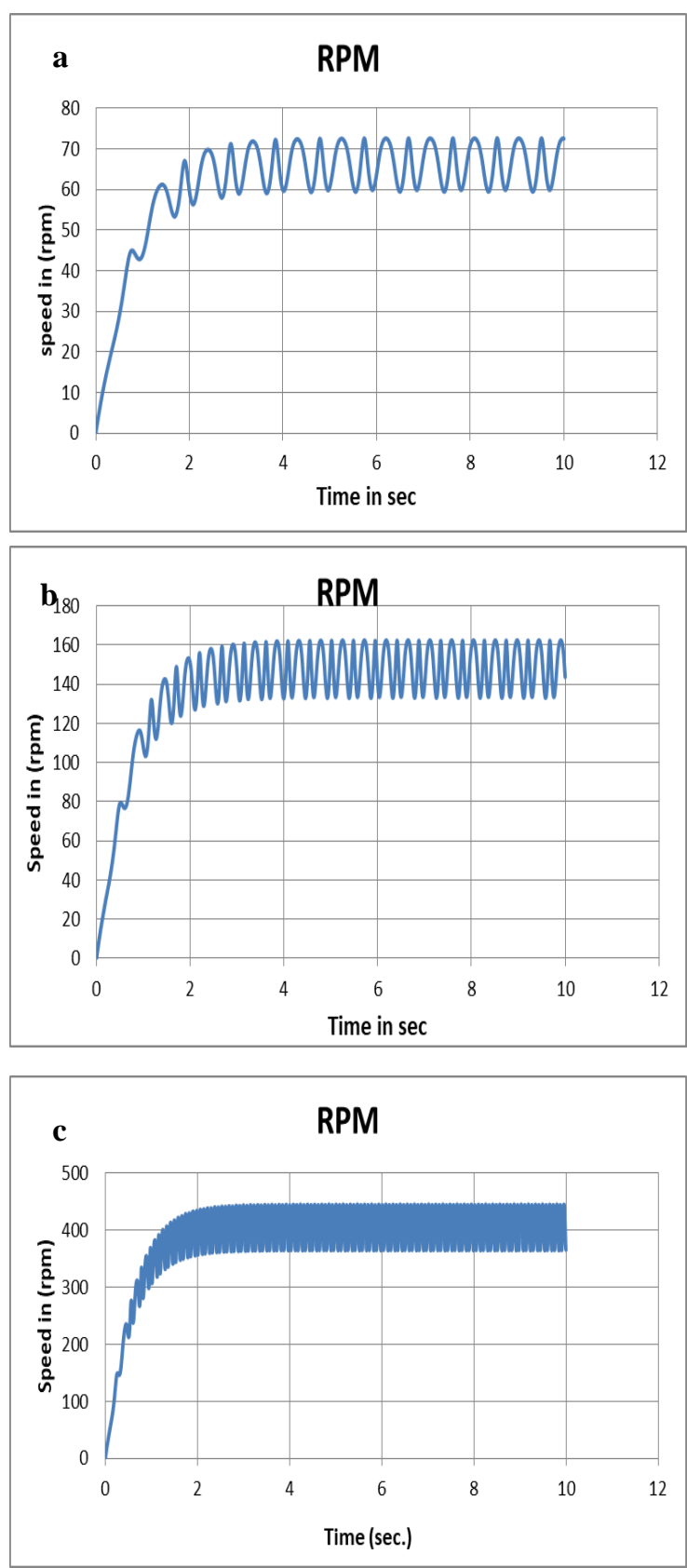

Fig.10.The speed variation with time for pressures value $(1,3,6$ bar) in a, b, c. 
The power of a rotating body can be expressed as:

$$
P=T 2 \pi \mathrm{N} / 60
$$

Where $\mathrm{P}=$ power in $(\mathrm{W})$

$\mathrm{T}=$ torque or moment $(\mathrm{Nm})$

$\mathrm{N}=$ speed in $(\mathrm{rpm})$

The variations of the engine power with the running time at different pressures are shown in Fig.11. The engine produces the maximum power of $3.17 \mathrm{~W}$ under the atmospheric pressure. The maximum power increases with the increasing pressure and reached the value of $117.8 \mathrm{~W}$ at charge pressure 6 bar. In comparison with Sripakagorn and Srikam [12], the power increased $23.48 \%$.

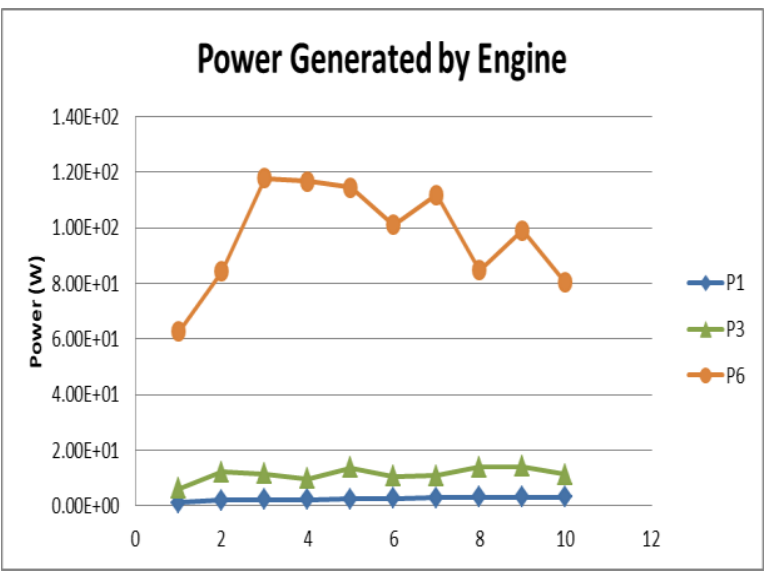

Fig.11.Power generated by engine.

In Fig.12 to Fig.14, the Von Mises Stress gradient determined by the analysis is displayed below graphically for different pressure values of $(1,3,6)$. Areas of greatest stress appear in red. As expected, there are regions with the highest stress concentration in the joints. The highest level of stress occurs where the crank port drives the rotational flywheel. In these cases, the maximum von Mises stress experienced by the flywheel is just over $24.278 \mathrm{MPa}$ at $6 \mathrm{bar}$. The steel flywheel possesses yield strength of over $350 \mathrm{MPa}$. in Fig. 15 ,represents the Total deformation that occurs in the flywheel surface for different pressures $(1,3,6)$ bar. The regions with the greatest distortion appear red.

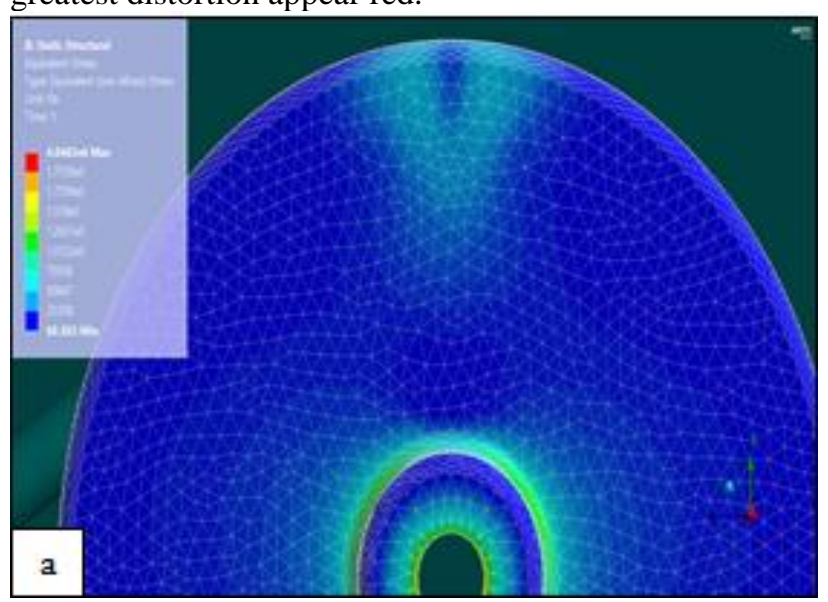

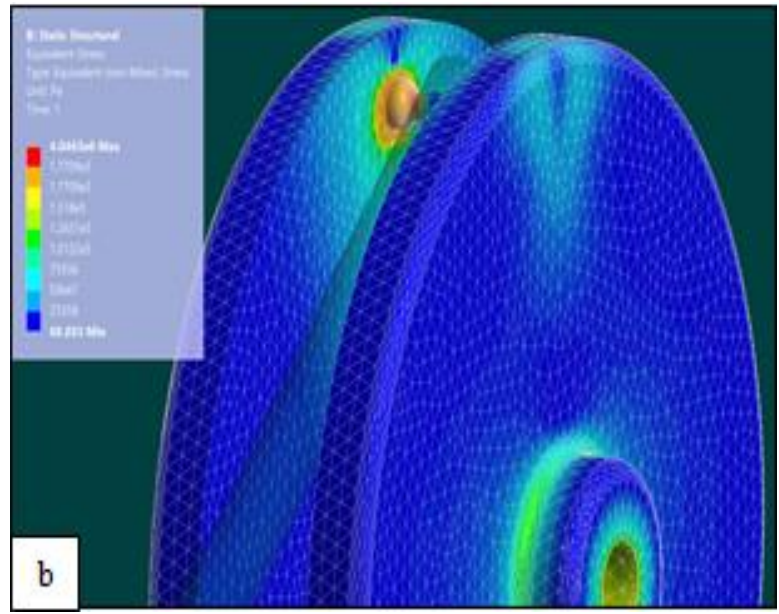

Fig.12. Von Misses stress distribution at 1bar
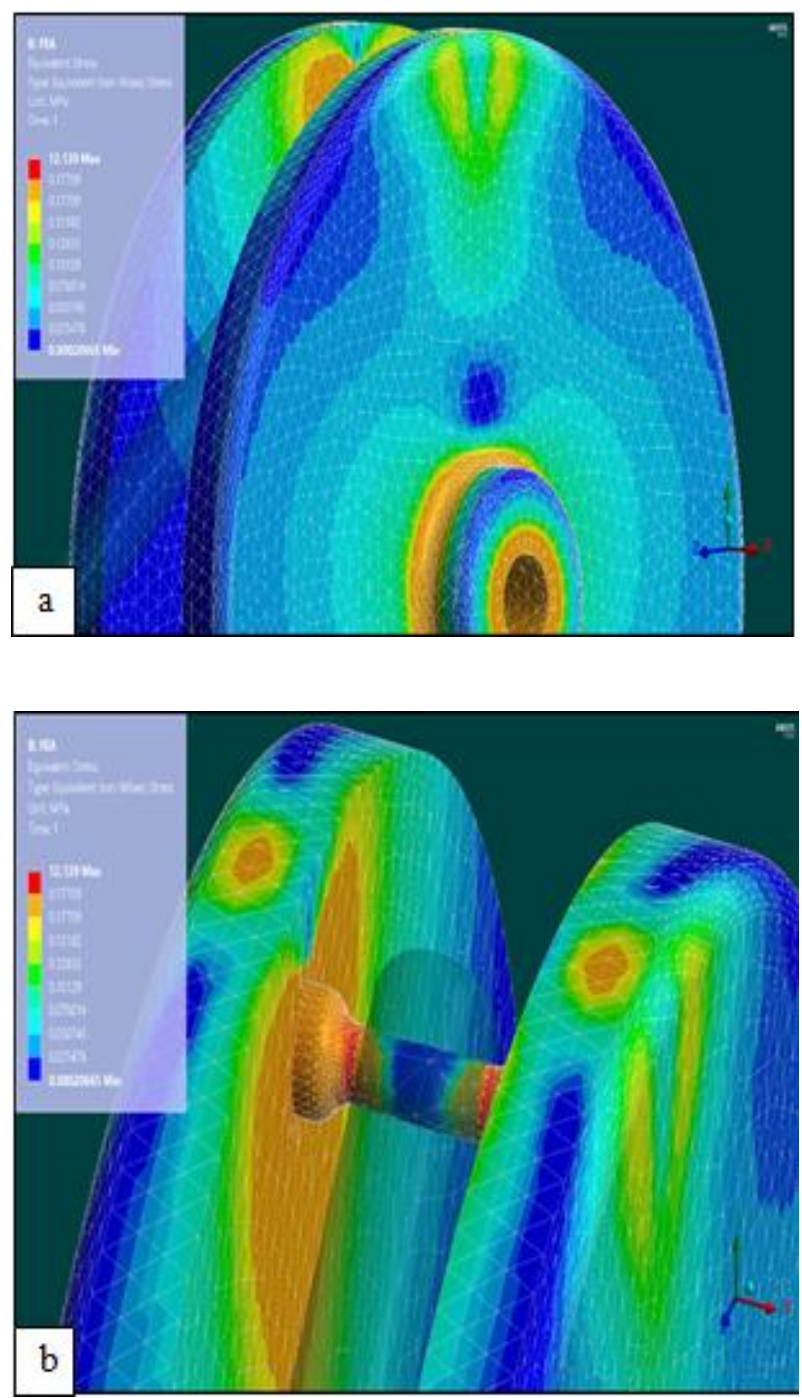

Fig.13. Von Misses stress distribution at 3bar. 

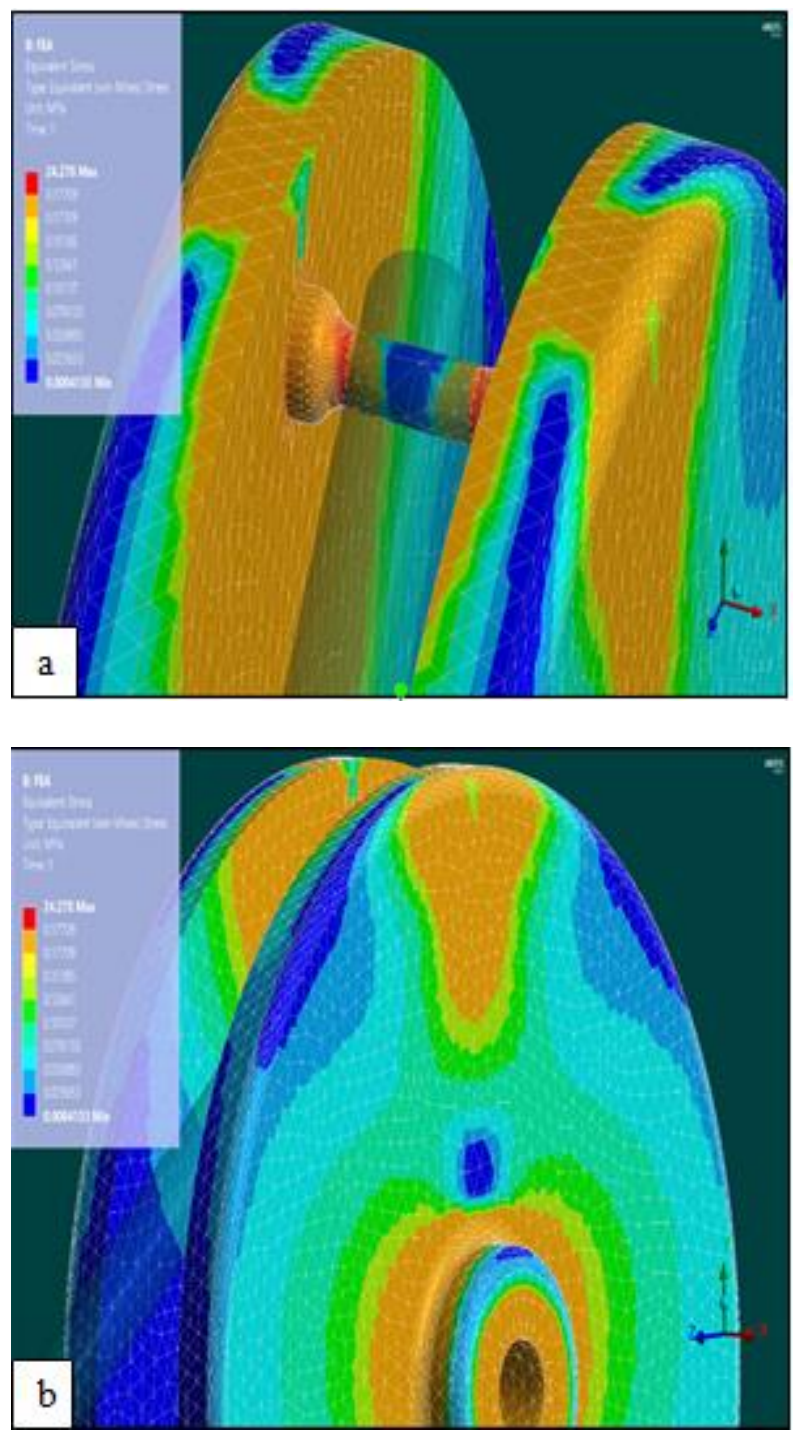

Fig.14. Von Misses stress distribution at 6 bar.

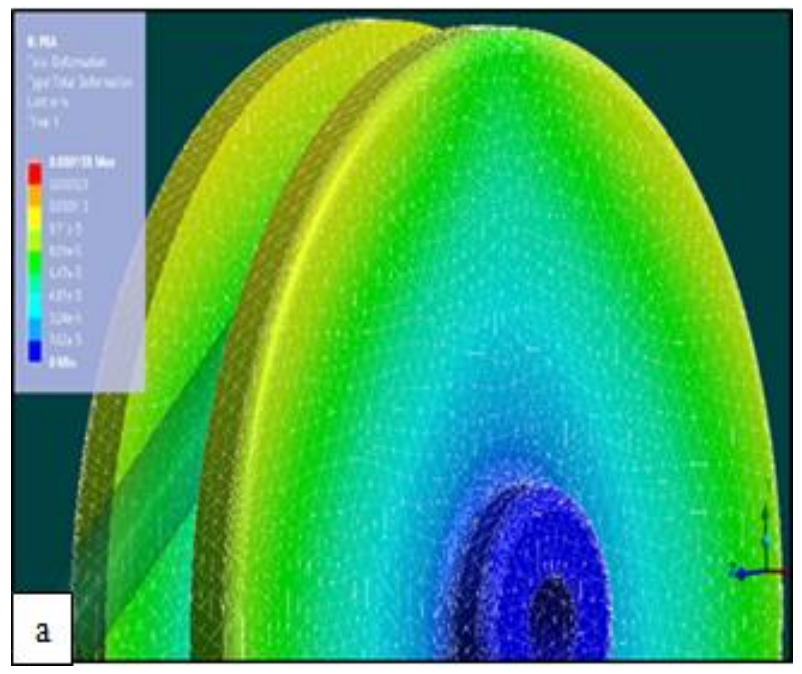

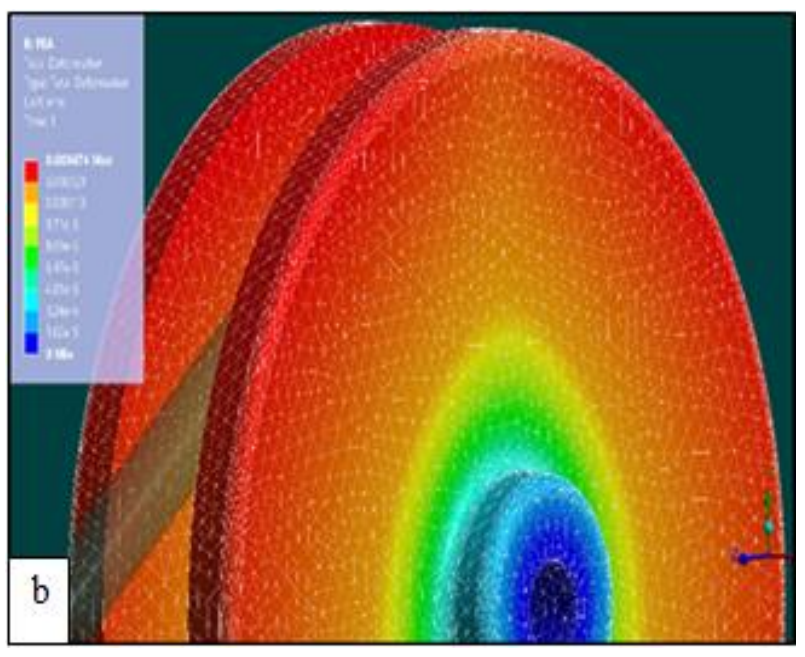

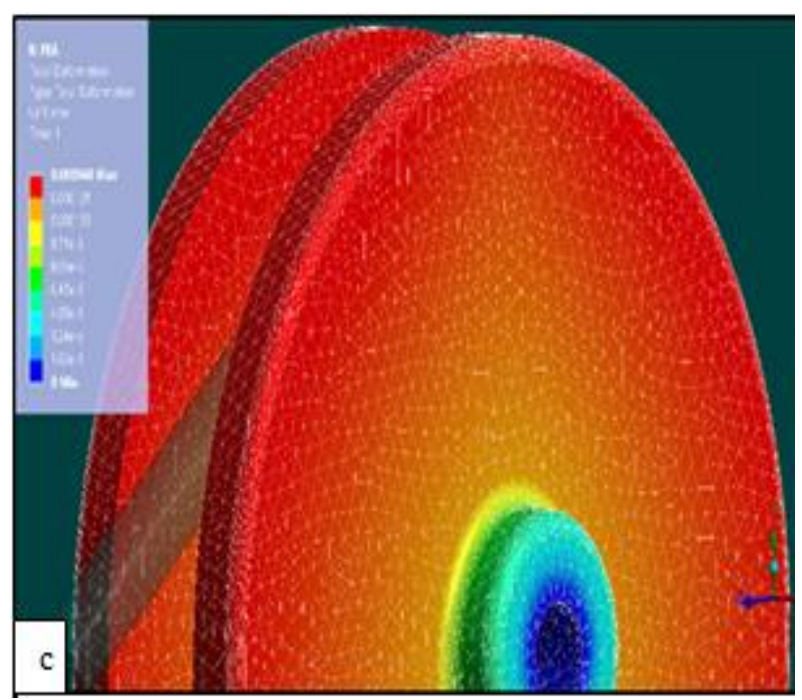

Fig.15 Total deformation at pressures values $(1,3,6$ bar) in a, b, c

\section{Conclusions}

In current work, the thermodynamic and mechanical analysis of a double-acting Stirling engine has been investigated in this paper by using ANSYS18.2 program. This theoretical study mainly studies the influence of the engine parameter (charge pressure and temperature) on the engine performances (engine speed, torque, and power output). The performance of the engine was examined for different values of the charge pressures (1, 3, 6 bar). For all charge pressures, Some main inferences acquired from the results above are offered as follows:

1- The torque and power output of the double-acting Stirling engine increases with increase charge pressure. The engine produced the maximum power and torque 117.8 W, 2.5404 N.m at 433 rpm when the charge pressure was 6 bars..

2 - The range of the running speed increases when increase charge pressure. 


\section{References}

[1] Walker G. Stirling engines. Oxford: Clarendon Press; 1980.

[2] Stine William B, Stirling engines ,In: The CRC hand book of mechanical engineers, Frank kreith \& yogi Goswami ,CRC Press, second Edition , pp.12631273,2015 .

[3] D. G. Thombare, S. K. Verma, Technological Development in the Stirling Cycle Engines, Science Direct, Renewable and Sustainable Energy Reviews, 12, 2008), $1-38$.

[4] B. Kongtragool, S. Wongwises, A review of solar powered Stirling engines and low temperature differential Stirling engine, Science Direct renewable and sustainable energy, 7,2003, $131-154$

[5] Schmidt G, Classical analysis of operation of Stirling engine, A report published in German Engineering Union (Original German), vol XV, pp1-12,1871.

[6] Finkelstein T. Computer analysis of stirling engines. Advances in Cryogenic Engineering 1975;20:269-82.

[7] Urieli I, Rallis CJ, Berchowitz DM. Computer simulation of Stirling cycle machines. In: 12th intersociety energy conversion engineering conference: 1977. p. 151221.

[8] Gupta RK, Deshpande AM, Brave KM. Development of $1 \mathrm{~kW}$ solar powered reciprocating engine for rural applications. In: International Solar Energy Congress, New Delhi. 1978. p. 2016-20.

[9] Kaushik SC, Kumar S. Finite time thermodynamic analysis of endoreversible Stirling heat engine with regenerative losses. Energy 2000;25:989-1003.

[10] Kongtragool B, Wongwises S. Thermodynamic analysis of a Stirling engine including dead volumes of hot space, cold space and regenerator. Renew Energy 2006;31:345-59.

[11] Timoumi Y, Tlili I, Nasrallah SB. Performance optimization of Stirling engines. Renew Energy 2008;33:2134-44.

[12] Sripakagorn A, Srikam C. Design and performance of a moderate temperature difference stirling engine. Renewable Energy 2011;36(6):1728-33.

[13] Akosy F, Solmaz H, Çinar C, Karabulut H. 1.2kW beta type Stirling engine with rhombic drive mechanism. Int. J. Energy Res.2017. 